\title{
HOT FORMING OF CAST STEEL CYLINDERS
}

\author{
${ }^{1}$ Jonathan URSINUS, ${ }^{1}$ Martin BONHAGE, ${ }^{1}$ Christoph BÜDENBENDER, ${ }^{2}$ Florian NÜRNBERGER, \\ ${ }^{2}$ Eugen DEMLER, ${ }^{1}$ Bernd-Arno BEHRENS \\ ${ }^{1}$ Institute of Forming Technology and Machines (IFUM), Leibniz Universität Hannover, Garbsen, Germany, \\ EU ursinus@ifum.uni-hannover.de, bonhage@ifum.uni-hannover.de, behrens@ifum.uni-hannover.de \\ 2Institut für Werkstoffkunde (Materials Science), Leibniz Universität Hannover, Garbsen, Germany, EU, \\ nürnberger@iw.uni-hannover.de, demler@iw.uni-hannover.de
}

https://doi.org/10.37904/metal.2019.820

\section{Abstract}

Regarding tool wear and energy consumption when forging steel parts, tailored preform geometries are beneficial. In particular, the number of forging steps can be reduced, in comparison to conventionally rolled cylindrical stock material, if preformed billets are used. In order to assess the potential offered by cast preforms as semi-finished products for a subsequent forging process, cylindrical steel billets (G42CrMo4) were cast by sand casting and then upset with different degrees of deformation $\varphi(0.7-1.5)$, forging temperature (600-1200 ${ }^{\circ} \mathrm{C}$ ) and ram speed $(30-700 \mathrm{~mm} / \mathrm{s})$. Forging of conventional rolled bar material under the same forming conditions was used as a reference. After forming, the specimens were heat treated and the mechanical properties were determined by tensile tests (DIN EN ISO 6892-1) and notch impact tests (similar to DIN EN ISO 148-1). The microstructures were examined by metallographic analysis. For the investigated process variables, no significant influences on the tensile strengths or impact energies of the cast and forged specimens were found. While the tensile strengths of the cast and forged specimens meet the values of conventionally rolled and forged specimens, the impact energies of the cast and forged specimens surpass those of the reference. This is attributed to compressed pores, which were incompletely closed during forging. A criterion for the design of a die forging process of cast preforms will be derived based on the obtained results.

Keywords: Hot forming, casting, steel, pore closure

\section{INTRODUCTION}

To further increase efficiency in the automotive and transport industries, forged high performance parts help to save weight and reduce the consumption of fuel or electrical energy. Although enhanced mechanical properties can be achieved by thermo-mechanical processing during forging, many intrinsic challenges exist. Mainly, flawless material flow leading to an appropriate form filling has to be ensured [1]. Starting from a simple semi-finished form with constant cross-sectional geometry, complex geometries are usually forged in several progressive steps. The design of the intermediate steps requires expertise and is limited by the capability of the forming equipment. The limited product design flexibility may have many consequences, including (but not limited to): low material utilisation, defective product production and longer run-up times. The reduction of the number of forging steps also bears potential to increase the economics of the production process itself. Fewer forging steps means reduced tooling costs, less wear and less machinery [2]. Therefore, the technology of forging complex shaped cast preforms and providing greater design flexibility is an attractive alternative to conventional die forging.

For non-ferrous metals, specifically aluminium, an economical motivation for a cast-forging process could be found, as the industrial Cobapress process demonstrates [3]. The combined casting and forging process of non-ferrous metals is frequently examined in the scientific literature. The investigated processes include single step cast-forging or rheo-forming [4], two step cast forging of solidified materials and the pressure casting with subsequent densification (known as squeezing) [5]. The idea of diverting form conventional steel rod material with constant cross-section to specifically cast preforms was first investigated and discussed in the 1980s by 
Ißleib et al. [6,7]. Since then, most of the research concerning the hot forming of cast steel deals with the free forming or open die forging of large ingots $[8,9]$. The application of this knowledge on pore closure or microstructure evolution to more conventionally sized die forging processes is missing in recent scientific literature. The aim of this study is to investigate the pore closure and elimination of casting defects in steel, and to provide a feasible process window for the cast-forging of more complex parts.

\section{EXPERIMENTAL}

Steel cylinders (G42CrMo4) were cast in a sand casting process. After the removal of the casting system, the cylinders were then hot compressed. The forming parameters (temperature, ram speed, plastic strain) were varied and their influence on tensile strength and impact energy investigated. All upsetting experiments were repeated with a conventional rod material as a reference.

\subsection{Casting}

For determining the casting parameters, according to Seo et al. [10], the sand casting system was set up based on simulation results achieved with MAGMASOFT® (Figure 1). The designed system allows the casting of 12 cylindrical parts with a diameter of $44 \mathrm{~mm}$ and a length of $74.5 \mathrm{~mm}$. Each part is equipped with a riser to ensure that the melt flows in to the casting part after filling the system. Since low-alloyed steels have high melting temperatures and poor casting properties compared to cast iron, different casting temperatures (1650$\left.1720^{\circ} \mathrm{C}\right)$ and casting durations (8-20 s) were simulated. The calculation results revealed that with a casting temperature of $1680{ }^{\circ} \mathrm{C}$ and a casting duration of $12 \mathrm{~s}$ the system can be filled without a premature solidification.

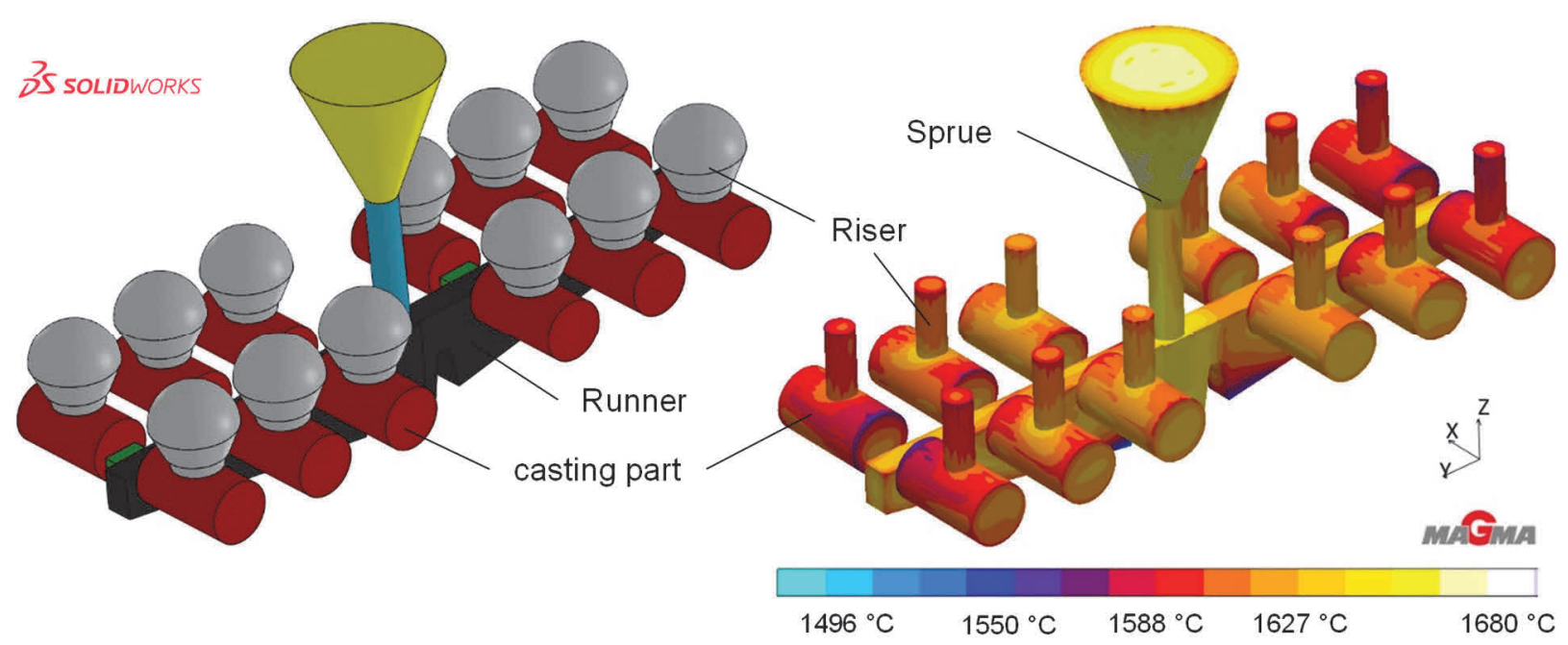

Figure $1 \mathrm{CAD}$ model (left) and simulation model (right) of the casting system for casting of cylindrical parts

A polymer (PLA) cast model was manufactured by additive manufacturing (3-D printer, Ultimaker). A sand mould was made using this model and prepared for the casting experiments. For the melting of the steel $42 \mathrm{CrMo} 4$, a tilt-pot furnace (Inductotherm) with a maximum filling capacity of $22 \mathrm{~kg}$ was used. The monitoring of the temperature during the melting process was carried out with a pyrometer. After reaching a temperature of about $1700^{\circ} \mathrm{C}$, the molten steel was cast within $10 \mathrm{~s}$ into the sand mould.

After casting, the cylindrical parts were separated from the casting mould and the surface was cleaned by sandblasting. The chemical composition of the casting parts was measured by optical emission spectrometry (OES) and is given in Table 1. Due to the casting, a lowering of the content of $\mathrm{C}$ and $\mathrm{Mn}$ occurred. However, the measured values correspond to the required values according to DIN EN 10293 for the alloy 42CrMo4. The microstructural analysis showed a pearlitic structure. 
Table 1 Chemical composition in wt.\% as determined using OES

\begin{tabular}{|l|c|c|c|c|c|c|c|c|c|}
\hline \multicolumn{2}{|l|}{ Elements } & C & Si & Mn & P & S & Cr & Mo & Fe \\
\hline before casting (42CrMo4) & 0.52 & 0.25 & 0.78 & 0.01 & 0.03 & 1.1 & 0.23 & Rest \\
\hline \multicolumn{2}{|l|}{ after casting (G42CrMo4) } & 0.35 & 0.18 & 0.53 & 0.01 & 0.03 & 1.1 & 0.23 & Rest \\
\hline $\begin{array}{l}\text { Values according to } \\
\text { DIN EN 10293 }\end{array}$ & Min. & 0.38 & - & 0.60 & - & - & 0.9 & 0.15 & - \\
\cline { 2 - 30 } & Max. & 0.45 & 0.4 & 0.90 & 0.35 & 0.35 & 1.2 & 0.30 & - \\
\hline
\end{tabular}

\subsection{Upsetting}

The deformation of the cast specimens was achieved by upsetting experiments. The experimental design was based on a two-step plan of the three variables: temperature, plastic strain and ram speed. Additionally, a central point with medium temperature and deformation was used. The global true strains of $\varphi=0.7-1.5$ correspond to slightly different local deformations in the centre of the specimens. The mean deformation of the investigated volume is similar to the global true strain and thus these values have continued to be used.

50 cast and 50 conventional cylinders were tested. The cast specimens were sorted by their density and then evenly distributed on the 10 parameter sets to minimise the effect of casting batch deviations. The cylinders were heated for $30 \mathrm{~min}$ in a batch furnace to their respective forming temperatures. The temperature was verified by thermocouple measurements. Two flat dies then applied the upsetting force. Their surfaces were lubricated by graphite spray (Fuchs Lubritech Con Traer G300). The use of two different presses allowed for two different ram speeds. The slower deformation took place on a hydraulic press (Schirmer und Plate) with a ram speed of $30 \mathrm{~mm} / \mathrm{s}$, while the fast upsetting was carried out on a screw press (Lasco) with about $400 \mathrm{~mm} / \mathrm{s}$ ram speed on contact.

\subsection{Mechanical Testing}

The compressed cylinders were cut with a band saw to extract the rough shapes of the later specimens for mechanical testing. These rough specimens of similar cross-section were then identically heat treated (QT to $25 \mathrm{HRC}$ ) to eliminate the influence of the heating history during hot forming. After heat treatment, a specimen for tensile testing and one for notch impact energy testing were machined. Thus, every compressed cylinder was represented by both tests. The geometry of the tensile specimens was chosen according to DIN 50125 type B $5 \times 25$. The notched impact energy tests were carried out in respect to DIN EN ISO 148-1. The tensile tests were carried out with a universal testing machine Z250 (Zwick/Roell) and the notched impact energy tests with an impact-hammer model PSW 750AF (AMSLER Prüfmaschinen AG).

\subsection{Metallographic Analysis}

Metallographic analysis was used to investigate the microstructure of the cast-forged specimens and to evaluate the pore closure by the forming operation. After the impact tests, selected specimens were ground and polished for light microscopy (microscope Polyvar MET). Images of pores were taken in non-etched conditions. After etching (5 \% $\left.\mathrm{HNO}_{3}\right)$, the microstructures were investigated.

\section{RESULTS}

\subsection{Mechanical properties}

The observed tensile strength of the specimens ranged from $706 \mathrm{MPa}$ to $843 \mathrm{MPa}$. Of all tested parameters, the forming temperature had the strongest influence on the measured tensile strength. Figure 2 shows the mean tensile strength and its standard deviation SD for all specimens compressed at $600{ }^{\circ} \mathrm{C}$ and $1200^{\circ} \mathrm{C}$. 
The conventionally rolled cylinders compressed at $600{ }^{\circ} \mathrm{C}$ showed a mean tensile strength of $802 \mathrm{MPa}$ $(\mathrm{SD}=6.8 \mathrm{MPa})$. The mean tensile strength of the conventional cylinders compressed at $1200{ }^{\circ} \mathrm{C}$ was $814 \mathrm{MPa}$ $(\mathrm{SD}=6.6 \mathrm{MPa})$. This is a small but significant $(\mathrm{p}<0.001)$ difference. The same general trend can be observed with the cast and compressed specimens. However, the greater standard deviation of those test results does not allow for a definitive statement.

The primary influence on the impact energy was the true strain. Again, significant dependencies could only be measured in the group of conventional rod material specimens. The mean of the conventional specimen deformed to $\varphi=0.7$ was $46 \mathrm{~J}(\mathrm{SD}=11 \mathrm{~J})$, whilst the mean of those deformed to $\varphi=1.5$ were $55 \mathrm{~J} \quad(\mathrm{SD}=10$ $\mathrm{J})$. Based on these results and a sample size of 20 each, a difference greater than $2.8 \mathrm{~J}$ can be safely assumed $(p<0.05)$. Similar to the results of the tensile tests, the general trend of an increase of impact energy with deformation can be observed in the cast specimens as well, without statistical significance. However, the impact energy levels of the conventional and the cast specimens are fundamentally different, with the cast and compressed specimens greatly surpassing the conventional reference. Some of the cast specimens showed a delaminated fracture surface similar to the descriptions in [11].
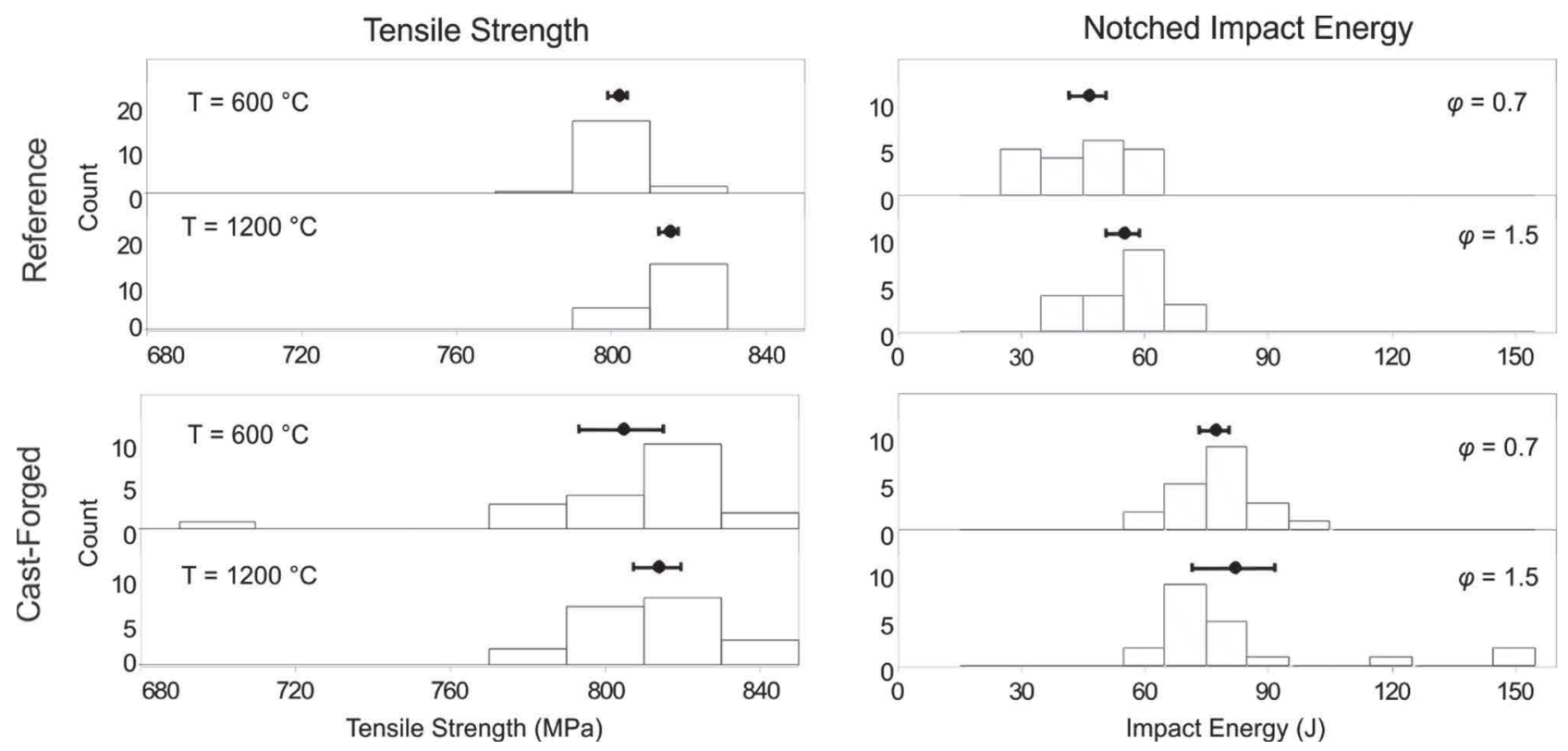

Figure 2 Histogram illustrating the influence of the strongest factor on tensile strength and impact energy, grouped by billet type. Mean values and SD are shown as black dots and bars.

\subsection{Metallographic Examination}

The main results of the metallographic examination are summarised in Figure 3. Picture a) shows an as-cast specimen after longitudinal cutting, polishing and etching. Remarkable are the large pores clustered in the direction of the riser, which were present in all cast cylinders. Additionally, a typical cast microstructure with pearlitic-ferritic structure and very large primary grains was observed. Figure 3b) and c) show microscopic images of a compressed specimen $\left(\varphi=1.5, T=600^{\circ} \mathrm{C}\right)$ in non-etched and etched conditions. The non-etched microstructure looked largely homogeneous, with few defects, which appeared dark and were all stretched perpendicular to the forming direction during upsetting. The etched microstructure in Figure 3c) revealed fine grain sizes and an orientated structure, corresponding to the material flow during upsetting. Although harder to detect, very few small and dark defects could still be found. 

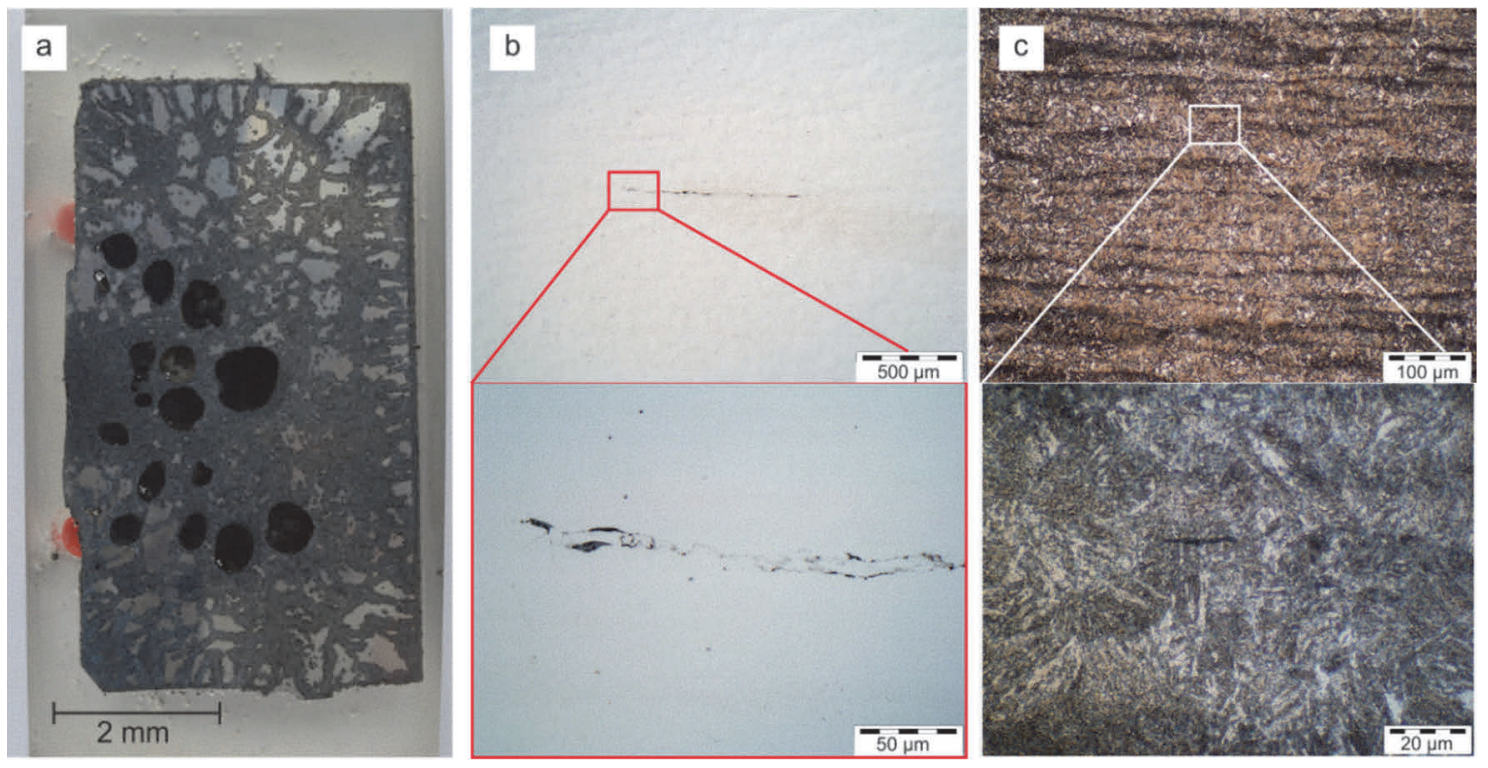

Figure 3 a) Porosity of the as-cast cylinders, b) defects after deformation (non-etched), c) defects after deformation (etched)

\section{DISCUSSION}

\subsection{Mechanical Properties}

The mechanical properties of both, the cast-forged and the conventional specimens were in the expected ranges. The very similar tensile properties indicate an identical heat treatment of all specimens. Generally, the mean deviation of the properties was lower for the conventional material. This can be attributed to chemical inhomogeneity and casting defects in the cast-forged microstructure. The mean strengths were practically identical. The results are promising for the eventual replacement of conventional hot forged steel parts by castforged parts. Nevertheless, a higher safety factor might be necessary if the property deviations cannot be reduced and further research has to establish fatigue property data.

\subsection{Microstructure}

Density measurements, metallographic imaging and the mechanical tests all indicate that independent of the forming parameters the pore volume could be removed or significantly reduced. The closure of these pores seems to be largely complete, as the mechanical properties and metallography suggest. However, there are still remnants of casting defects detectable in all parameter combinations. It is unclear why most of the pores close, but some do not. A possible explanation might be the entrapment of gases or other non-metallic residue during casting. These contaminated pore surfaces are then unable to be welded.

The delamination occurring during the notch impact tests of the cast-forged specimens is also an indicator for the existence of weaker planes, caused by the orientated deformation of the microstructure and the defects. This effect was also observed by other researchers in hot rolling processes [11]. Further research will be devoted to investigate anisotropic material properties due to cast-forging.

\subsection{Criterions for pore closure}

The simplest criterion for the design of a hot forming process of cast preforms is a minimum requirement for the plastic strain. This is easy to implement into numerical process design routines and is robust in application as it is not dependent on microstructural parameters. Published values for this lower limit range from $\varphi=0.6$ [12] to $\varphi=1.4$ [13]. There are more complex formulae presented in literature which take the pore size, shape or surface into account [9]. Obtaining these parameters and then controlling the casting process to stay within 
acceptable tolerances requires a well-established process chain. For the general use, we propose a minimum true strain of $\varphi=0.7$ to ensure equal to conventional mechanical properties of cast-forged steel (G42CrMo4).

\section{SUMMARY}

A cast-forging processing route has been tested for the upsetting of steel cylinders to establish base knowledge on the behaviour of casting defects in small forged parts. Tensile strength tests and notched impact fracture tests were conducted to assess the elimination of porosity and casting defects. The cast forged specimens showed similar tensile strengths and higher impact energies than the reference. A local true strain equal or greater than $\varphi=0.7$ leads to a removal of pore volume. The influence of forming temperature or ram speed on the pore closure was negligible.

\section{ACKNOWLEDGEMENTS}

The presented results are based on the research project "Precision Forging of Cast Preforms", Project number 351032371 . The authors would like to thank the German Research Foundation (DFG) for the financial support.

\section{REFERENCES}

[1] BEHRENS, B.-A., DOEGE, E., REINSCH, S., TELKAMP, K., DAEHNDEL, H. and SPECKER, A. Precision forging processes for high-duty automotive components. Journal of Materials Processing Technology. 2007. vol. 185, no. 1-3, pp. 139-146.

[2] BEHRENS, B.-A., BOUGUECHA, A., LÜKEN, I., MIELKE, J. and BISTRON, M. Tribology in Hot Forging. In: Hashmi, S., eds. Comprehensive Materials Processing. Oxford: Elsevier, 2014, pp. 211-234.

[3] PERRIER, F., DESRAYAUD, C. and BOUVIER, V. Microstructural and mechanical evolutions during the forging step of the COBAPRESS, a casting/forging process. In: Weiland, H., Rollett, A.D. and Cassada, W.A., eds. ICAA13 Pittsburgh. Cham: Springer International Publishing, 2016, pp. 1691-1696.

[4] MATHEW, J., MANDAL, A., WARNETT, J., WILLIAMS, M.A., CHAKRABORTY, M. and SRIRANGAM, P. X-ray tomography studies on porosity and particle size distribution in cast in-situ Al-Cu-TiB 2 semi-solid forged composites. Materials Characterization. 2016. vol. 118, pp. 57-64.

[5] ZHOU, H.T., XU, S.X., LI, W.D., WANG, S.C. and PENG, Y. A study of automobile brake bracket formed by casting-forging integrated forming technology. Materials \& Design. 2015. vol. 67, pp. 285-292.

[6] IBLEIB, A., NEUBAUER, A. and PRIETZEL, K.O. Grundlegende Untersuchungen zum Gesenkschmieden in Kokille gegossener Ausgangsformen. Gießereitechnik. 1980. vol. 26, no. 7, pp. 204-206.

[7] AMBOS, E., NEUBAUER, A. and OSWALD, J. Kombination von Ur- und Umformen - ein Weg der Verfahrensintensivierung in der Teilefertigung. Gießereitechnik. 1983. vol. 29, no. 4, pp. 102-106.

[8] ZHAO, J., JIANG, Z. and LEE, C.S. Enhancing impact fracture toughness and tensile properties of a microalloyed cast steel by hot forging and post-forging heat treatment processes. Materials \& Design. 2013. vol. 47, pp. $227-$ 233.

[9] HAURI, J., GRAF, M., AWISZUS, B. and KAWALLA, R. Closing of Shrinkage Cavities by Means of Open-Die Forging. Materials Science Forum. 2018. vol. 918, pp. 77-84.

[10] SEO, H.-Y., JIN, C.-K. and KANG, C.-G. Design of a gate system and riser optimization for turbine housing and the experimentation and simulation of a sand casting process. Advances in Mechanical Engineering. 2018. vol. 10, no. 8, art. n. 1687814018795045.

[11] INOUE, T., YIN, F., KIMURA, Y., TSUZAKI, K. and OCHIAI, S. Delamination Effect on Impact Properties of Ultrafine-Grained Low-Carbon Steel Processed by Warm Caliber Rolling. Metallurgical and Materials Transactions A. 2009. vol. 41, no. 2, pp. 341.

[12] LEE, Y.S., LEE, S.U., VAN TYNE, C.J., JOO, B.D. and MOON, Y.H. Internal void closure during the forging of large cast ingots using a simulation approach. Journal of Materials Processing Technology. 2011. vol. 211, no. 6, pp. 1136-1145.

[13] KAKIMOTO, H., ARIKAWA, T., TAKAHASHI, Y., TANAKA, T. and IMAIDA, Y. Development of forging process design to close internal voids. Journal of Materials Processing Technology. 2010. vol. 210, no. 3, pp. 415-422. 